\title{
Intricacies Related To Retirement
}

\author{
NG'ANG'A Elijah \\ BED \{ARTS $\}$, MBA \{HRM $\}$ PHD(Candidate) \\ (Kenyatta University-School of Business).
}

\begin{abstract}
The relationship between employment and retirement is changing dramatically in industrialized societies, with a decreasing proportion of working life being spent in stable career progression. Many who retire from long-service career jobs now seek paid employment in bridge jobs before completely exiting the labor force. There is little research about the effects of employment transitions and instability in later life on health, but limited research on instability early in the working life does show a strong and significant relationship. Instability is found to be associated with adverse health effects, with variability by gender and type of health measure. In addition, both objective and subjective transition characteristics are related to variability in health. In this regard, this paper will explore on different aspects related to retirement, issues like, countering aging population, philosophical concern on retirement, support to retirees and variables associated with retirement. A voluntary separation occurs when an employee separates from employment due to resignation, retirement or job abandonment. Retirees commonly face four risks that can threaten to derail their retirement: work life initiatives, health care, sequence of returns, and financial status. These risks pose a multifaceted challenge that requires a combination of strategies, such as carefully choosing when to claim Social Security, allocating assets to lifetime income annuities, adopting a systematic withdrawal strategy, and planning for longterm care. This article offers a range of ideas and insights to help organizations offer the best support to retirees so that they can achieve a more secure retirement.
\end{abstract}

Key words: Employment transitions, voluntary separation, Aging population, ContinuityQ Theory,

\section{Concept background}

\section{INTRODUCTION}

Population aging, caused by poor work life initiatives, financial bottlenecks, lower fertility rates and family circumstances., is a topic of increasing importance in many of the world's industrialized nations (Brown2011; Cooke 2006; McDaniel and Rozanova 2011; McDonald and Donahue 2011; Statistics Canada 2006). Work life initiatives and financial planning will also inevitably lead to rapid population aging in the developing world, where currently the median age is substantially lower than that of the developed world. In fact, the gap between the median ages of the developed and developing worlds is shrinking (Bongaarts 2004). In response to the concern that this potent demographic trend could lead to labour force shortages, national governments and some international organizations must go a little deeper in coming with long time initiatives to counter the situation. Including havingefforts to increase the rates of participation of older individuals in the labour force. A country like Canada according to research is among the nations that have made efforts to address the consequences of a rapidly aging population (Cooke 2006). Statistics show the magnitude of population aging in Canada. Between 1981 and 2005, the proportion of Canada's population made up of those aged 65 years and older increased from 10 percent to 13 percent, and it is expected that population aging will accelerate over the course of the next three decades (Cooke 2006). While in 2011, those over 65 years of age comprised 14 percent of the Canadian population, it is expected that by 2036, seniors will comprise 25 percent of Canada's population (Statistics Canada2012). The 
near future will involve massive numbers of people leaving the workforce as members of the baby boom generation, those born between 1946 and 1964, reach their retirement years (Brown 2011; McDonald and Donahue 2011; McMullin and Cooke2004; Rix 2004). These demographic trends have led to concern among many policymakers and employers that the near future will be characterized by a shortage of skill and of business knowledge, and that the Canadian health and income safety nets will be compromised (Statistics Canada 2008). Some research suggests that this situation will be compounded by the fact that older workers are less productive than younger workers because of differences by age in the adoption of new technologies, in health status, and in levels of effort while at work (Tang and MacLeod 2006). One strategy that has been utilized in Canada to manage the rapidly aging population is the enactment of policy that encourages the immigration of young workers (Fougère et al. 2004). As immigrants to developed countries are of a lower average age than the resident populations, increased immigration is a means through which developed nations can counteract population aging (Bongaarts 2004). Fougère and his colleagues (2004:210) emphasize the importance of immigration in Canada:In this respect, in comparison to other industrialized countries, Canada has one of the highest inflows of immigrants relative to its population. In fact, without the contribution of immigration, both the population and the labour force would eventually decline in the future. They further emphasize that maintaining high rates of immigration could limit increase in the Canadian elderly dependency ratio, a measure of the number of elderly individuals in a population in relation to the number of individuals who are of working age.

\section{Towards retirement \&separation}

An employee who is appointed to a limited or casual/restricted position is automatically terminated as of the last day of the appointment, unless there is an earlier separation or a formal extension of the appointment in writing which must be well booked and rehearsed. This notion will form a strong background in this article since it will open up the thin deference between retirement and separation. What then is the difference between the two terms:

Different definitions of retirement lead to different conclusions about the retirement patterns of women and men. Defining retirement as "not working or looking for work" at specific ages always counts more women than men as retired at each age. However, if one looks at selfreported retirement, women are often less likely to be retired than men. The major source of difference is the nonmarket work of women, including care giving responsibilities for children, parents, spouses, and other relatives, as well as housekeeping tasks culturally expected of women. For example, one study found that over 20 percent of women in their fifties and early sixties were not in the labor force due to reasons other than retirement, compared with only 8 percent of men. At the same time, more men than women considered themselves to be retired.

As there is no single best definition of retirement, it is appropriate to tailor the definition of retirement to whatever question is being asked. If one is interested in when workers decide to collect pensions and/or Social Security benefits, it is appropriate to treat retirement as an event. Another kind of research focuses on the economic and social well-being of retired people. In this case, retirement is considered to be a stage of life rather than an event. Most such research considers everyone who has reached a stated age, usually sixty-five, as retired, regardless of whether they continue to work. Less commonly, two or more criteria are combined. For example, only people over sixty-five who are not in the paid work force may be included in the retired population. Multiple definitions of retirement are useful in addressing specific questions about differences in men's and women's decisions about leaving the paid work force, and about their economic well-being after the age when people's active working lives usually end. 
To be noted then is that generally, an employee separation describes any event that separates the employer and the employee. Some human resources practitioners refer to "separation" as the process of informing the employee of the termination, completing paperwork for continuation of benefits and retrieving company property from the employee. Other HR practitioners distinguish between separation and termination based on why the employee is no longer employed

\section{Emphirical Review \\ Philosophical Approach}

The notion of out: "Out of sight, out of mind" should not at all be a tagging philosophy to justify poor practices exhibited while attending to retirees. However, most organizations and those charged with the responsibilities of handling retirees use this philosophy at times. One major concern here should be to bring together the organization and retirees when circumstances warrant that to happen; the philosophy is therefore heart breaking and at times demeaning.

\section{A new beginning, not the beginning of the end}

Philosophically speaking, retirement has the potential to be one of the most exciting times of your life as, in most cases, it gives you the best of both worlds - flexibility of time yet fewer of the numerous responsibilities you previously had. Even if your time and resources are not as flexible as you would like, your transition into retirement can provide an exhilarating opportunity for you to redesign your life in the way that you want it to be. Philosophically, a holistic approach will lead you to enjoying a happy and meaningful retirement; focusing solely on your finances is short-sighted. Your financial plan and the plan you have for your life are intertwined, so the way you structure your investments depends on what you want to do with your money. You therefore need to define what is important to you at this vital stage of your life, and then make sure you align your financial plan with your new priorities. Its encouraged that you look beyond your financial commitments to the place where money and meaning meet.

Patrickson and Ranzijn (2005) suggest that older workers generally do not seek career advancement. Therefore, older workers might likely be less affected by the "out of sight, out of mind" phenomenon as compared with younger workers. Moreover, the invisibility of aging workforce has the potential to separate workplace judgments about an older worker's performance from judgments about an older worker. The aging workers may also reduce exposure from stigmatism (Patrickson, 2002).

\section{REVIEW OF THE LITERATURE}

This chapter will provide a background to and a context for the investigation of the topic of retirement, employment after retirement which is of key importance in the present reindustrialized world that is facing a rapidly aging population and concomitant labor force shortages, through a review of relevant literature.

Discussions of efforts aimed at increasing the labour force participation of older adults must acknowledge that the norms surrounding age are socially constructed (Gubrium and Holstein 1999; Hendricks and Achenbaum 1999; McMullin 2010; Turner1989). McMullin (2010) links the social construction of societal conceptions of age with the age stratification theory of aging when she claims that the way in which the meanings of age are constructed in any society will determine the norms concerning the ages at which different roles are adopted or abandoned. In this sense, policy efforts to encourage work in the later years are attempts to socially reconstruct the meaning of age in a manner that will be beneficial within the contemporary 
context. Some scholars have argued that the increasing value placed on productive work and work ethic that has accompanied modernization is linked to the reduction of the status of the elderly (Cowgill 1974). Thus, from this perspective, finding effective ways to keep older adults in productive work will raise the levels of status they enjoy. This review of the literature will begin by addressing three theories of aging that are highly pertinent to the topic of return to work after retirement They are: Disengagement Theory, Activity theory, and Continuity Theory. Some policy implications of these theories will be explored.

\section{Theoretical Insights Relating to Productivity and Aging}

For the most part, the continuity, activity, and disengagement theories of aging each elaborate upon a different dimension of the phenomenon of growing older. However, these theories are also composed of ideas that stand in opposition to one another. This opposition is largely based on the fact that these theories of aging hold elements of prescription beyond description and explanation. For instance, proponents of disengagement theory view old age as a time during which elderly individuals gradually recede from active involvement in the surrounding community (AchenbaumandBengtson 1994; Connidis and Willson 2011; Cumming et al. 1960; Cumming and Henry1961; Maddox 1963; McPherson 1990; Moody 2010; Turner 1989). This disengagement is seen as a natural process that is functional for both the elderly individual and the larger society (Cumming et al. 1960). Turner (1989:597) provides a succinct statement of disengagement theory when he claims: In so-called disengagement theories, it is argued that with ageing people begin to relinquish certain social responsibilities and expectations in order to engage more fully in personally rewarding leisure activities. As the elderly withdraw from social roles, society as it were disengaging from the ageing in order to bring about neutral process of declining reciprocity.

The activity theory of aging is considered the opposite of that of disengagement (Connidis and Willson 2011; Moody 2010; Turner 1989). Proponents of this theory argue that the more active and involved elderly people are, the more satisfying their lives will be (Connidis and Willson 2011; Lemon et al. 1972; Longino and Kart 1982; McPherson 1990; Moody 2010; Turner 1989). As elderly individuals are likely to maintain the values and needs of their earlier years, they are likely to proceed with the social roles and activities of their past (Lemon et al. 1972). Turner (1989) suggests that post-retirement experiences tend to be related to one's previous style of life and social standing. These latter points tie activity theory with a similar perspective on aging known as continuity theory, which proposes that successful aging occurs when elderly individuals maintain a lifestyle similar to that of their earlier years (Atchley 1989; McPherson 1990; Moody2010).

\section{The Disengagement Theory of Aging}

The disengagement theory of aging was first explicitly formulated by Elaine Cumming and her colleagues in 1960, and then elaborated by Cumming and Henry in1961. Cumming and Henry's disengagement theory, proposed in Growing Old (1961), was the first attempt made by gerontologists to develop a multidisciplinary and explicit theory of normal aging, as opposed to aging characterised by senescence and gradual decline (Achenbaum and Bengtson 1994). In 1960, Cumming and her colleagues suggested that elderly individuals cooperate with their surrounding community in a gradual process of mutual separation, or disengagement. They traced this idea back to Durkheim, who in Suicide (1897/1951:215) stated that, Society is still lacking in [the child], for it has not had the time to form him in its image; it begins to retreat from the latter [aged at the last confines of life] or, what amounts to the same thing, he retreats from it. (bracketed text added by Cumminget al. 1960:25) 
Cumming and Henry (1961) argued that as many of the connections between elderly individuals and their social surroundings are severed, those that remain undergo a change of quality. Social relationships, for example, become more horizontal and egalitarian rather than vertical and based on differences in power (Cumming and Henry 1961).

The disengagement theory of aging is also derived, at least in part, from Talcott Parson's functionalist ideas of social adjustment. Elderly individuals benefit from this separation because their loss of skill, knowledge, and energy with advancing age make it impractical for them to remain highly productive and engaged with their social surroundings. Disengagement of the elderly is also of benefit for society because it frees up positions in paid work and in other domains for the entry of young individuals, thereby ensuring that young individuals undergo the training they will need to eventually take up positions of authority while also ensuring that the elderly are disengaged before they undergo the loss of skill that will compromise their performance in important social roles (Achenbaum and Bengtson 1994).

Disengagement theory is functionalist also because, according to this standpoint, the disengagement of the elderly from society safeguards against their deaths causing disruptions to the larger social system (McPherson 1990). This theory of aging is related to modernization theory because it holds that the status of the elderly, by necessity, must decline with the increasing efficiency of society that accompanies its modernization. This makes the disengagement of the elderly a natural process (Moody 2010). Since the initial studies from which it developed and since its first explicit formulation, the disengagement theory of aging has been a topic of controversy, on both the empirical and theoretical levels. Cumming and Henry (1961) developed their theory

from a 10-year longitudinal study of later life aging known as the Kansas City Studies of Adult Life. Disengagement theory was developed as an explanation for the findings of this study (Cumming and Henry 1961). Some of the researchers involved found that with age, individuals develop an increasing interiority in which they focus more and more on their own inner psychology. They saw elderly individuals as becoming increasingly detached from their social environment with the passage of time in anticipation of the role losses that will accompany their advancing age (Moody 2010). Cumming and her colleagues (1960) studied a total of 211 people, a portion of who were between the ages of 50 and 70 years and were a part of the Kansas City studies, and the remainder of whom comprised a sample of mobile elderly individuals aged 70 to 90 years. They found their sample of older individuals to be somewhat eccentric, carefree, and egocentric.

They attributed these traits to a decreased level of social control born of the gradual disengagement of this sample of older individuals from the larger society. Some research provides limited support for Cumming and Henry's (1961) idea that elderly individuals experience constraints on the activities in which they have the opportunity and motivation to take part and on the roles that the surrounding social structure permits them to adopt. Maddox (1963) accumulated empirical evidence that showed that some elderly subjects are able to maintain high levels of morale even in the absence of high levels of activity and of interpersonal contact. He speculated, in accordance with Cumming and Henry (1961), that psychological disengagement is an anticipatory coping strategy that allows elderly persons to neutralize the demoralizing impact of the structural disengagement that will accompany their advancing age. He further suggested that with advancing age, social activity is less likely to be associated with high levels of morale because decreased social engagement results in fewer critical evaluations and sanctions on the part of others that are distressing for aging individuals. 
Although Maddox (1963) found a general positive association between activity and morale, he used these suggestions to argue that this positive relationship is not inevitable.Tallmer and Kutner(1969) found patterns of disengagement in their sample of older individuals in the U.S. that they attributed to the significant physical and social stressors that accompany old age and that dramatically impact the lifestyles of older individuals.

Despite this empirical support, many criticisms of both a theoretical and empirical nature have been made of disengagement theory. Other empirical work conducted in the U.S. has shown that withdrawal is not the usual pattern (McPherson 1990). Furthermore, disengagement is a heterogeneous phenomenon, as people in different social circumstances show disengagement to differing degrees (McPherson 1990). These criticisms point to what is probably the main argument against disengagement theory: it falsely assumes the universality of increasing disengagement with advancing aging (Connidis and Willson 2011; McPherson 1990). This assumption is made despite the fact that the elderly form the age group that is the most likely to be heterogeneous because

they have had the longest time available to accumulate unique sets of experiences (Connidis and Willson 2011). McMullin (2000, 2010) emphasizes that class, age, gender, and race/ethnicity form interlocking structures, the effects of any one of which cannot be understood without examining them all as an interactive whole. Any difference between two individuals in any one of these structures will lead them down different life trajectories (McMullin 2000, 2010). The older the two individuals are, the more lifetimes they will have undergone over the course of which their life trajectories will have continued to diverge. As such, greater heterogeneity among the elderly is an outcome of the interplay of social structural forces.

Disengagement theory has been criticized from a number of additional angles.Connidis and Willson claim that some have criticized this theory for "effectively putting older people on the shelf for the benefit of society's smooth functioning" (2011:206). Others have noted that there is some ambiguity concerning the behaviour that falls under the label of "disengagement." An individual might withdraw from one set of activities only to be able to invest more time and effort in another set of activities (Moody 2010).Cumming and Henry (1961) themselves argued that elderly individuals will undergo a crisis if they do not find a new set of roles, congruent with the disengaged state, to replace the roles that have been abandoned. Cumming and Henry's (1961) analysis has-been criticized for being cross-sectional instead of longitudinal and for being based on a sample whose representativeness of the larger elderly population of the U.S. could be questioned (Maddox 1963). Also among the arguments used to contradict disengagement theory is the claim that retirement generally leads to a period of poverty and decline in social status for elderly individuals, instead of being a stress-free "golden age" of ample time to become involved in a range of enjoyable leisure activities. Studies conducted in the U.S. show that disengagement in old age usually occurs because of illness rather than being a natural outcome of the natural process of aging (Turner 1989).Achenbaum and Bengtson (1994) discuss numerous criticisms that have been made of disengagement theory based on a number of criteria that are often used in the evaluation of scientific theories. Some have criticized the logical adequacy of the theory

by claiming that it is too functionalistic or too one-dimensional in certain regards. Concerning the operational adequacy of the theory, it has been claimed that the outcome variable, successful aging, cannot be subjected to empirical testing. Some have argued that this outcome is more a matter of personal values than it is an objective outcome that can be operationally defined. Concerning the criterion of empirical adequacy, disengagement theory has been 
criticized at its source as other members of the Kansas City studies research team, including Neugarten and her associates (1964), were not generally led to the same conclusions as those arrived at by Cumming and Henry. Further empirical investigations subsequent to the Kansas City studies also failed to show a universal pattern of disengagement with the progress of age in later life. With regards to the criterion of pragmatic adequacy, this theory contradicts the efforts of social workers and of administrators who strive to keep the elderly active and engaged in life (Achenbaum and Bengtson 1994). Social workers have promoted the physical activity of their older clients because such activity can help them feel good and maintain a high quality of life. Some have even argued that physical activity on the part of the elderly has the potential to save the health care system a substantial amount of expense (Marshall and

\section{Countering Aging Population}

\section{THEMATIC ISSUES}

Various strategies are adopted in to counter the ramifications of population aging for example the encouragement of the labour force participation of older individuals. Statistics Canada's $A$ Portrait of Seniors in Canada (2006:124) elaborates upon the need to keep older persons in paid employment: With possible shortages in the labour market looming, policy makers and employers are searching for new ways to retain older workers on the job. Could older workers potentially be interested in staying longer in the workforce if certain choices were offered to them? The 2008 Expert Panel on Older Workers for example emphasized the potential benefits to older workers and to the Canadian economy more broadly of policies and programs that will encourage and support the labour force participation of older individuals. It also promoted increased freedom for older individuals to determine their own labour force involvement and argued for the removal of obstacles and of disincentives that might prevent the engagement of older individuals in paid work (Denton and Spencer 2009).

Despite concerns that older workers may keep jobs from younger workers, numerous justifications have been offered for increasing workforce involvement in later life. Among them are the fact that life expectancy has increased, that lower levels of morbidity imply a healthier and more capable older labour force, that intergenerational equity requires that older individuals retire at a later age, and that prolonged labourforce involvement is beneficial for the financial well-being of older individuals (McDonald and Donahue 2011). In fact, increased later life labor force involvement has been depicted as a positive trend that will help ensure that rising life expectancy will be paid for through employment instead of through financial transfers from younger generations to older generations (Ekerdt 2009).

In response to recent demographic and economic changes, new forms of retirement have developed, among them an emerging pattern of returning to work after one's first retirement (McDonald and Donahue 2011). This phenomenon is often referredto as "bridge employment." The meaning of this term is well-depicted by Pengcharoenand Shultz (2010) who refers to bridge employment as any part-time or full-time transitory employment pursued after having left one's career employment. It thus provides a transition stage between full-time employment and complete labour force exit (Dendinger, Adams, and Jacobson 2005; Pengcharoen and Shultz 2010). Throughout this article, this term will be used when reference is made to those who have engaged in paid work after a first retirement.

The importance of the topic of work in later life has led some researcher's to investigate the factors associated with whether an older individual will return to thelabour force after his or her retirement. Some research has found a positive relationship between measures of social status and involvement in post-retirement work (Cahill,Giandrea, and Quinn 2006; Griffin and Hesketh 2008; Lefebvre, Merrigan, and Michaud2011; Maestas 2010; Raymo et al. 2010; 
Statistics Canada 2006). Other studies have shown that those of younger age and those who have retired at a younger age are morelikely to engage in paid work after their retirement (Cahill et al. 2006; Davis 2003;Griffin and Hesketh 2008; Lefebvre et al. 2011; Maestas 2010; Statistics Canada 2006).

Regarding marital status, studies have not found a substantial difference between the married and the unmarried in rates of paid work after retirement (Davis 2003; Lefebvre et al. 2011).Number of interactions among them are associated with the likelihood that one has engaged in paid work after a first retirement. A study concurs with Cooke's (2006)emphasis on the need for policy promoting work in later life to consider a life course approach that acknowledges how events earlier in life impact later life circumstances, as well as how multiple life domains, including those of education, work, family, and health, interact in influencing the decisions people make. It seeks to develop knowledge concordant with a life course approach that can aid in the formulation of policy that can effectively prolong the working lives of Canadian citizens.

There may be benefits of continued work activity for older individuals. Past studies have produced some conflicting results concerning whether older persons benefit by remaining involved in formal activities. To the detriment of the quality of life of older individuals. In addressing the issue overpopulation aging, variables must be looked into. Questions must be answered; it would be socially unjust to retain older persons in the workforce for the benefit of the economy if this retention is to the ultimate detriment of their own quality of life.

\section{Workers' vision of a flexible retirement requires support from employers}

The New Flexible Retirement notion which illustrates that today's workers are expecting to transition into retirement but face a significant obstacle: few employers have employment practices to support them."Population aging is a global phenomenon. The shift toward a proportionally smaller working-age population and larger older population is disrupting traditional employment models and the fundamental economics of government-sponsored social security systems around the world," said Catherine Collinson(2000).A flexible retirement, which offers workers the ability to pursue their own personalized transition, can create opportunities to work longer, continue earning income, and stay active and involved in society. Moreover, a new flexible retirement can create a win-win situation by serving as a powerful tool to help solve the government, social security, and employer-related retirement issues resulting from an aging population. The most common reasons for continuing to work to some extent in retirement include keeping active, enjoyment of work, and financial-related concerns. This new report is based on research from the Aegon Retirement Readiness Survey 2015, comprising 16,000 workers and retirees. It presents global trends and profiles for 15 countries, offering unique perspectives on the state of flexible retirement in Europe, the Americas, Asia, and Australia and includes recommendations for policymakers, employers, and workers.

\section{How do workers envision their retirement?}

"The concept of retirement is changing rapidly. As people live longer and in good health, retirement is becoming a more active life stage, with more people looking for the opportunity to combine work and leisure," said Collinson.(2000). "Many workers have embraced retired the notion of fully retiring at age 60 or 65 .Globally, the survey found that 51 percent of all workers now expect to retire at age 65 or later, or not at all. The mindset of working beyond traditional retirement age varies around the world; in Japan, 43 percent of survey respondents aspire to continue working past retirement compared to only 15 percent in France. More than half (56 percent) of workers globally envision a flexible transition to retirement; with 55 
percent of those age 55 and older, and an even higher proportion of younger workers, holding this vision. The most common reasons for continuing to work to some extent in retirement include keeping active, enjoyment of work, and financial-related concerns.

\section{Employers can do more to support a flexible retirement}

How workers can successfully extend their working lives is a complex issue. Collinson 2000, Workers in jobs that involve manual labor may find it difficult to continue in their current profession. Others may encounter workplace biases against older workers. Employers play an allcritical role and can make or break workers realizing their vision of a flexible retirement.Workers indicate that their employers are doing little to help them phase into retirement. The survey found that only 27 percent of workers age 55 and older say their employers offer the opportunity to shift from full-time to part-time working arrangements as they phase into retirement. Only nine percent of workers age 55 and older say their employer offers retraining opportunities to extend their careers and help them phase into retirement. "Maintaining existing job-related skills and acquiring new ones are important for workers of all ages and especially for older workers who want to work past normal retirement age," quotes Collinson. Employers can do more to help their older employees keep their skills up-to-date. Despite the lack of pre-retirement assistance from employers, older workers are nevertheless loyal. Almost half (48 percent) of workers age 55 and older say they feel a strong sense of belonging to their employer and 73 percent say they plan to work with their current employer until they retire, if possible according to the survey by Collinson.Employers may be overlooking the opportunity to tap into the knowledge, skills, and loyalty of older workers. By adopting business practices to support a flexible retirement, employers can benefit from improved succession planning and the ability to optimize their workforce management,Heyma (2004).

\section{Transition into retirement}

Policymakers, employers, and workers each play a critical role in redefining retirement, retirement benefits, and employment practices to keep step with increases in longevity and the implications of population aging. The retirement packages in many governments offers a full set of recommendations, including:

All Governments should consider reforms to social security benefits that can positively influence workers' behavior and attitudes to retirement. Examples include increasing the age at which government benefits begin and providing enhanced benefits for those deferring their entitlements.

1. Governments should identify and remove disincentives in social security and workplace retirement plans to working past a fixed retirement age. Examples include the ability to start receiving retirement benefits while continuing to work.

2. Employers can and should promote an aging-friendly work environment and culture designed such that workers of all ages thrive. Flexible work arrangements and ongoing training help workers maintain a good work-life balance and keep their skills current.

3. Employers should conduct a review to see how changing demographics will affect their workforce and assess the value of retaining older workers as a way of retaining institutional knowledge and address potential labor shortages in the future.

Pienta (1998), a clear strategy for promoting the new flexible retirement can benefit workers, employers, and governments in addressing the challenges created by population aging and building retirement systems that are affordable, sustainable, and achievable for all. 


\section{What influences the (early) retirement decision according to previous research?}

Retirement has always been an important topic, especially now, since the most governments are discussing what needs to be adjusted in the retirement system to be able to cope with the growing amount of elderly individuals. The factors that are found will be projected adequately on their significance in the explanation of the (early) retirement age.

Two main situations can be recognized which could force people to retire. These two options of involuntary retirement are layoffs and health, which can both only indirectly be influenced by policy (Heyma, 2004). But what happens when an employee is not obligated to retire? What aspects will then influence his or her retirement decision? The factors that influence the retirement decisions are divided into three categories: work incentives, family circumstances and financial incentives. However an important remark will be made when early retirement is not an attractive option, individuals will seek for alternatives. This phenomenon is called "communicating vessels". Communicating vessels is the interaction between early retirement and the retirement packages.

Heyma (2004) states that the structure of the benefit and pension program is the most important determinant of retirement. However, in his research Heyma (2004) also states that the benefits that a worker gets, do not play an exclusive role. This implies that there are more incentives that influence the (early) retirement decision. In the following sections a summarization is given on the literature that was regarding the influences on the (early) retirement decision.

\section{Workplace initiatives}

Work conditions can be a determining factor to retire, these conditions influence the preferred retirement age. When work is physically demanding, or possibly more tiring, it will increase the probability of retirement, especially retirement through disability. The work status of a job has also a significant influence, Pienta (1998) found that especially men who have a higher work status in their job, have lower or delayed retirement preferences. A possible explanation for this is that men, more than women, identify themselves with their role as employee.

The attitude of the employee towards working longer is supposed to influence the age of retirement, according to Henkens et al. (2009). However a positive attitude of the employer has less influence on the retirement decision than a negative attitude. According to Heyma (2004) is the retirement decision an optimal choice between consumption and leisure. When making this optimal choice, the employee takes the working conditions, health conditions and the risk of involuntary retirement into account.

The incentive of an individual to work depends also on the years of education of an individual. When an individual is lower educated, he or she will have entered into the workforce earlier and is intended to retire earlier to. This means that the work incentive around the age of (early) retirement will be lower for individuals who are lower educated. This is one of the main findings from Henkens and Kalmijn (2005). They found that the number of years of education as well as the level of education influence the (early) retirement age. Lower educated individuals have a 2.4 times higher chance to leave the labor market through disability or unemployment than higher educated individuals.

In the case of the PFZW- participant the health care sector can be seen as a tough job. In general health care employees have physically demanding tasks. This means that the work circumstances in this sector can lead to early retirement. However, work circumstances are often subjective, this means that it is difficult to include this in the data analysis. Therefore the 
height and status of a job and the attitude of an individual towards a job will also be difficult to include in the data analysis. Education is a variable that can be measured, however PFZW is not allowed to have this information of its participants and therefore it is not in the data analysis. The only work-related factor, which can be included in the data-analysis, is the part-time factor. With the part-time factor it can be studied what the optimal decision is between work and leisure.

\section{Family circumstances}

Gustman and Steinmeier (2000) state three main explanations for the fact that labor force participation of older married couples is strongly positively correlated; State dependence, Assortive mating and Joint pension schemes. State dependence refers to the fact that couples usually create the same preferences in leisure, therefore they will prefer retirement together. Assortive mating means that individuals usually find their partner in an individual who has the same preferences and therefore they will also prefer retirement around the same time. Next to this, spouses arrange their financial administration together and therefore often have retirement schemes that match. According to Blau and Gilleskie (2001) the fact that spouse arrange financial administration jointly is an explanation for the strong correlation between health insurance, retirement and employment for couples.

Following Johnson and Favreault (2001), family is an aspect that influences the rate of retirement for husbands differently than for wives. When taking a closer look at the retreatment from the labor force, in order to spend more time with the family, husbands are more likely to retreat as opposed to wives. Blau and Gilleskie (2001) confirm this finding in their research. Pienta (1998) finds that women are better able to combine work and family roles during their life. Clark et. al (1980) find in their research that individuals respond positively to increases in their own wage but tend to reduce labor-force participation as the wage of their spouse increases. It is tried to extend the research into a family framework, in which it is studied if the retirement of the husband and wife is jointly determined. The research is concluded with the answer that wage and health are important determinants of joint laborforce participation. It is also found that the probability of employment of a person increases whenever the spouse is employed. Heyma (2004) confirms thisHeyma (2004) confirms this, when an employee has an employed partner, the probability of retirement is significantly lower. The probability of retirement is especially low when the employed spouse faces disability or unemployment. So it can be concluded that spouses take joint retirement decisions.

Coile (2003) points out an important factor of retirement incentives; the spill-over effects on the husband's retirement decision. However, the spill-over effects of the husband's incentives on the wife's retirement are found to be small and statistically insignificant. However the other way around, the effect of the financial incentives of the wife on the husband turn out to be significant. These results have several important implications. Women are primarily influenced by their own economic variables and do not just follow their husbands in making a retirement decision. It can be concluded that joint modeling of the retirement decision of couples would be appropriate. Johnson and Favreault (2001) estimate that 22 till 40 percent of husbands and wives retire within a period of two years. In addition to this, Gustman and Steinmeier (2000) state that the rate of retirement for married employees increases when one of the spouses is retired or unemployed. Blau (1998) states it even more strongly than Johnson and Favreault (2001); about a third of the couples, in which both spouses are employed, retire within one year of each other. 


\section{Financial incentives}

According to Lumsdaine and Mitchell (1999) financial incentives explain about half of the observed variation in the retirement patterns. These financial incentives consist of multiple sub-incentives of which the most important ones will be briefly discussed below.

Belloni and Alessie (2009) focus on Social Security Wealth (SSW) and its influence on an early retirement decision. SSW represents the total of financial incentives that determine the retirement decision. The higher the SSW, the higher the probability that an employee will decide to retire. Belloni and Alessie (2009) also conclude that female employees react more heavily to financial incentives compared to male employees. They also found that by becoming eligible for pension benefits, a change in the financial incentives occurs and this results in an increase of thirty percent in the probability of retirement. In addition to this the article written by Heyma (2004), states that female workers retire sooner than male workers.

In Euwals and Trevisan (2010) it is stated that theory has shown that where there is no pension system or when the pension system is neutral or actuarially fair, people retire when the marginal utility of inactivity is equal to their marginal productivity at work. Euwals and Trevisan (2010) conclude with the statement that people in poor health and with low productivity will retire earlier than people in good health and with high productivity.

The fiscal attractiveness of early retirement seems interesting to employees, but according to Heijdra (2008) these options act as a trap. Heijdra (2008) states this since it induces most workers to retire before the normal retirement age. This can be explained by the trap that Heijdra (2008) discusses which induces individuals to retire earlier than they otherwise would have done.

According to Heijdra (2008), the tax system influences the optimal retirement decision in two ways. The first one is the substitution effect, which is negative. A higher tax leads to a discouragement towards employees and therefore encourages them to retire earlier in life. The other effect is the wealth effect which turns out to be positive. The increase in the amount of tax to be paid, makes the employee poorer and in this way provides the employee with an incentive to retire later in life. 
3.0 Conceptual framework and important variables on retirement.

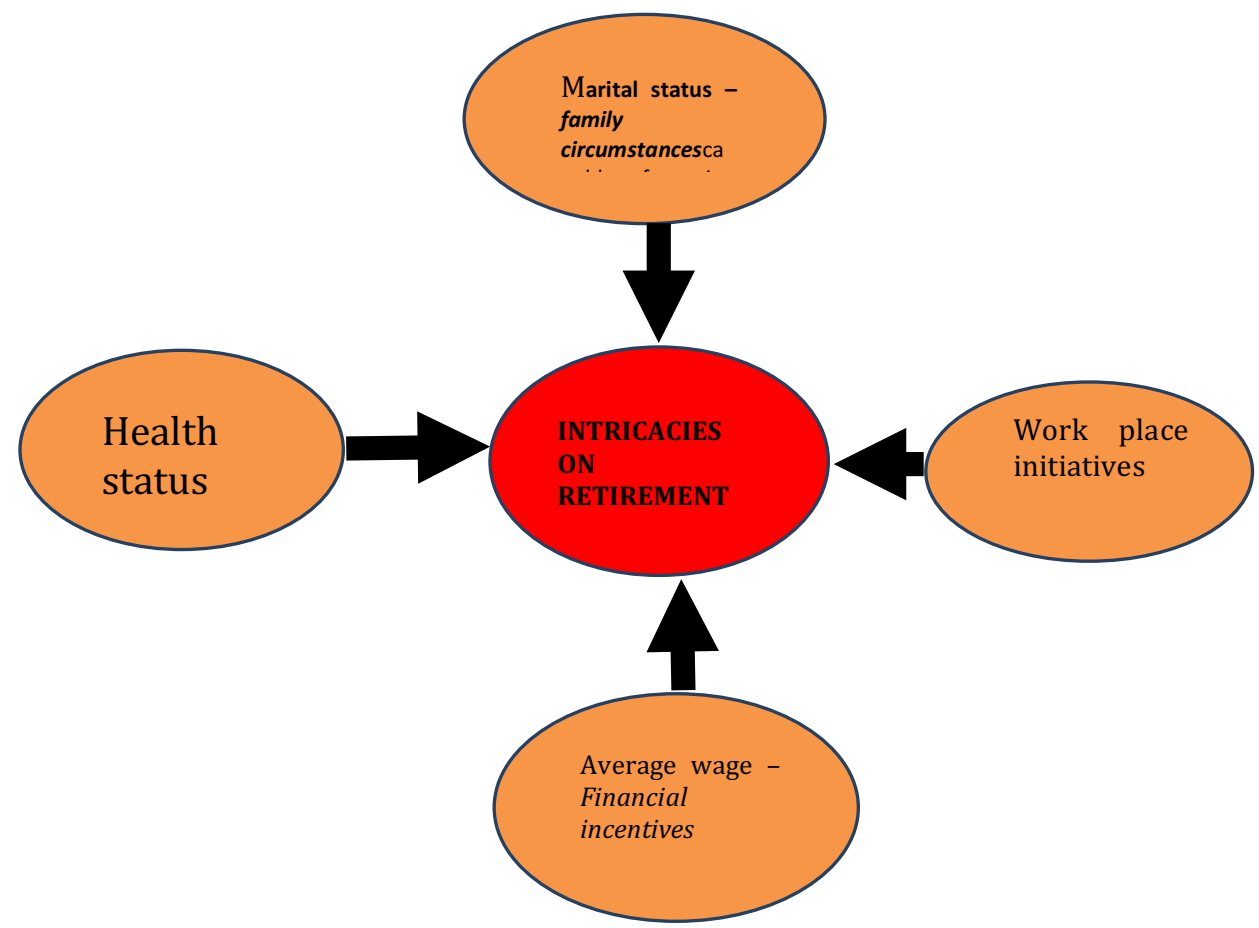

Fig 1.0 Conceptual frame work Source: Researcher 2017

\section{Managements' blended work bias}

\section{OVERSHADOWING RETIREMENT}

Among the greatest opponents of blended work are managers who rose within an organization by working in traditional environments. They fear the loss of control over employees; lack of trust has also been associated with low blended work opportunities (Lamond, 2000). Other major reasons why blended work has not been widely implemented by managers are likely the concern of deterioration of organizational communication (Raiborn\& Butler, 2009) and company identity (DiMartino\& Wirth, 1990), which they perceive could lead to detachment. Gibson and colleagues (2002) state that leadership models that comprise in-house teamwork and rapid customer response may be contradictory to home-based work. By incorporating retired workers into the system, this will enhance overshadowing of the retirement since old but productive workers will get a chance to serve.

\section{Differential training bias based on age}

Certain characteristics of computer work could be novel and require substantial costs and periods of training for the older worker. For example, for remote computer tasks involving sales, support, graphics, programming, and data analysis, employee training could take as long as three to over 6 months (Friedberg, 1999). However, research suggests that costs and time related to training on unique software applications for essential work-related tasks might be differentially provided by age and employer. Friedberg (1999) found that while management paid nearly $40 \%$ of financial costs for in-school training, workers aged 60-64 are more likely to pay for all costs associated with training and less likely to be given time off than their younger counterparts.

Similarly, older workers could have more difficulty than younger workers regarding assistance needed for example computer training. Despite the likelihood that older workers would require greater assistance for training on ICT, findings indicate a differential bias exists in favor of younger workers (Bennington \&Tharenou, 1996). Loretto and White (2006) report 
managers may exclude older workers from training on new technologies. Rupp, Vodanovich, and Crede (2006) note managers often view older workers as having lower economic worth to their organization. One consequence may be that older workers are less likely to be given structured computer training than younger workers (Martin, Dymock, Billett, \& Johnson, 2014).these differentiation and discrimination should be overcome by incorporating all the old workers.

\section{Issues of trust}

As noted above, trust influences which employees are allowed to blend work. Managers are more likely to allow professionals than clerical workers to blend work (Mokhtarian, Bagley, \& Salomon, 1998). Although many older workers in professional positions are trusted and perceived by managers as more reliable than younger workers to complete a project regardless of location (Stein \& Rocco, 2001), Barth, McNaught, and Rizzi (1993) describe a vicious cycle of employment practices. They report that although managers consider older workers to be more reliable and loyal, their attitudes toward them are often ambivalent. Negative stereotypes among managers include labels that older workers are rigid, resistant to supervision, and irritable. This perception could portend a self-fulfilling prophecy of employability for older workers ( $\underline{\text { Sterns \& Miklos, 1995) }}$, particularly if blended work requires substantial supervision (T. D. Golden, 2009).

\section{Negative perceptions about technological skill and fit}

Managers might consider younger workers more likely to fit a blended worker personality than older workers (Raiborn\& Butler, 2009), as the former are often perceived to be more productive and become easily bored (Martin, 2005). While this last trait might be disruptive in traditional workplaces, it could make younger workers appealing to managers seeking blended workers (Raiborn\& Butler, 2009). Managers also often assume that younger blended workers have greater technological skills for knowledge jobs. Component processes of cognition, such as the retrieval of remembered knowledge, decline with age (Salthouse, Kausler, \& Saults, 1990). Layoffs are commonly made on the basis of knowledge, skills, and worth to an organization. If older workers are perceived as less knowledgeable and skilled than younger workers to blend work, their employment may be terminated (Raiborn\& Butler, 2009).this perception should be overcome since age may not necessary be a benchmarking tool on productivity if skills are given to the work force on equal measure.

\section{Costs to organizations}

Employer costs for ICT at home could be greater than at a traditional workplace to establish, maintain, and update telecommunication systems, which are crucial for blended work. Employers might have to provide a variety of equipment and software for blended workers, such as multiple computers, a camcorder for videoconferencing, internet access with highspeed broadband, and a cellphone, fax, copier, scanner, and printer (Barron, 2007). The role of the communication and information technology department is vital for the blended worker, as the department often has to create a firewall and business-specific software (Behtash, 2008). In addition to these expenses, organizations might incur higher costs if they purchase adaptive and assistive technologies to offset potential declines in physical or cognitive functioning in older blended workers. Examples of assistive technologies to compensate for these declines include speech synthesis systems with built-in word vocabularies, grammar-based word prediction, low-vision magnifiers, and electronic page turners (Dishman, Matthews, \& Dunbar\acob, 2004).

Although physical and cognitive functioning and mobility are highly variable with aging, older workers are more likely to have compromised biological systems than younger workers. Older 
workers experience more lost workdays than younger workers (Laflamme\&Menckel, 1995), possibly indicating that after an injury recovery is poorer and severity is greater (Silverstein, 2008). The increase in injury severity associated with older workers could lead to greater operating costs for organizations in order to comply with the Occupational Safety and Health Administration (OSHA) Act and when purchasing Workers' Compensation insurance. For example, under Workers' Compensation (WC) for home-based work, if a blended worker sustains a severe injury while $s /$ he is working from home and the injury is directly related to work, OSHA will consider this a recordable work-related injury. Employers will generally be liable, possibly leading to fines and higher WC premiums (Raiborn\& Butler ,2009).

\section{Lack of co-worker support}

Walls, Safirova, and Jiang (2007) found that employees wanting to blend work are employed part-time, have higher educational levels and job control, have more job tenure, and are older. A survey by the Behavior Research Center (Gibson et al., 2002) found that individuals who blend work have an inter-quartile age range between 40 and 49 years. If older workers are more likely to blend work than younger workers, adverse workplace consequences may result, such as lower job satisfaction and increased turnover intentions among the coworkers employed in traditional workplaces (T. D. Golden, 2009).

Traditional workplace employees may also perceive blended workers as having more job flexibility and control. Coworkers employed in traditional workplaces might report increased frustration, erratic workloads, and interruptions due to "absent" colleagues from work teams in organizations that blend work (Kurkland\& Bailey, 1999). Workplace employees frequently believe that blended workers have a negative impact on team performance when work requires immediate and personal collaboration (Raiborn\& Butler, 2009). Coworkers may experience increased restrictions if they have to adjust their tasks and schedules to conform to blended workers; additional work tasks for these workers may also be required in the absence of the blended worker (T. Golden, 2007).

\section{Assistive technology}

Sterns and Miklos (1995) report that older workers may compensate for changes in learning, memory, and speed with crystallized knowledge, that is, knowledge that comes from prior learning, rooted in experiences (Cattell, 1963). Interventions that could substantially alleviate cognitive declines associated with aging might consist of incorporating crystallized knowledge using auditory or visual cues within assistive technology. This might help older workers anticipate functions present in new applications and prepare them to map new techniques and procedures to established ones (Sharit et al., 2009). Likewise, abilities and performance tests suggest the need for assistive technology to help older workers' focus attention on completing tasks while keeping track of multiple items (Sharit et al., 2004). Organizational interventions that ensure older workers have a range of assistive technology based on their capabilities and limitations could help focus the older worker's attention on one or several pending work activities.

Another intervention might consist of a data dictionary. Older workers report it would be helpful to have a glossary of terms with more background information, particularly in the home environment since technical support may not be easily available (Hill, Ferris, \&Märtinson, 2003). Using terms linked to the task, Sharit and colleagues (2004) observed that older workers were able to learn tasks that reflected their abilities and difficulties in adapting to technically oriented work environments, such as those that may be encountered in blended work. 


\section{Blended work as an employee benefit}

Proponents of blended work state that the recruitment of talent and reinforcement of human capital may encourage employers to implement blended work as an employee benefit for those with tenure and organizational loyalty; this would likely influence whether older workers remain with an organization (Claes\& Heymans, 2008). Since many blended workers with good ICT skills often self-select into blended work (Peters, Tijdens, \&Wetzels, 2004), another potential intervention is to develop a specific career track for blended workers who already work at the organization, with specific selection criteria, such as seniority, as a pathway to blend work.

Businesses that encourage blended work among older workers could mitigate the loss of knowledge capital at the organizational level. Knowledge capital is based on experiences with business processes that veteran employees share with coworkers in order to improve work efficiencies (Law Dictionary, 2015). Older workers frequently have organizational breadth, depth, and knowledge that crystallized intelligence and long-term experience often provide, which can then be transferred to younger colleagues.

\section{Management training}

Remote supervision requires setting timely goals between managers and employees to measure outcomes, including quality, output, and productivity. Managers often have little experience in remote supervision practices, which often leads to frustration and failed blended work policies (Kowalski \& Swanson, 2005). Interventions are required to train managers in remote supervision.

As previously noted, managers often assume that younger workers match a blended worker personality better than older workers (Raiborn\& Butler, 2009). Managers also frequently believe that older workers have difficulty adapting to new work environments and are resistant to change, although little research supports these stereotypes (Bennington \&Tharenou, 1996). Indeed, older workers are characterized by loyalty (Roberts, 2006), wanting to remain productive and connected to their professional identities (Sharit et al. 2004; Ulrich \&Brott, 2005), and wanting to form a collective purpose to achieve a common organizational goal (Ulrich \&Brott, 2005). While agreeing on outcome measures between a manager and the older blended worker may be as effective as with a younger co-worker, interventions are required to educate managers about the capabilities and stereotypes of the older worker.

\section{Training and educational funding}

Interventions by government that contribute to increasing educational achievements in ICT among nonprofessional workers are likely to increase blended work among less skilled older workers, but these should be combined with targeted tax credits to employers willing to provide this education (Walls et al., 2007). Similarly, since low skilled older workers might have a difficult time finding meaningful work, a suggested intervention strategy would be to provide blended work training to blue and so-called "pink" collar workers, coupled with tax incentives to employers with imminent labor shortages (Van Horn \&Storen, 2000).

Managers may be uninformed about governmental policies regarding employment and funding opportunities to train older workers. Federal grant funding options exist for accessing ICT and related equipment that could be used to train older blended workers. Similarly, the many government Departments of Labor's (DOL) Employment and Training Authority has developed protocols to train older workers on employment barriers. State-worker programs funded through institutions serve a substantial number of older workers, focusing and tailoring 
funding based on their training needs. Nonprofit organizations have established programs to help older workers remain in the workforce.

\section{Legislation directed at delaying retirement}

In the United States, delaying retirement among older workers by changing into less physically demanding jobs, such as blended work, might be facilitated if Congress acted to eliminate the "retirement earnings test" (RET) and "adjustment of the reduction factor" (ARF). The former withholds social security benefits to workers under the age of 66 if they earn too much, while the latter is a social security earning's penalty if a worker between 62 and 66 years of age earns too much. Eliminating the RET and ARF might encourage older workers to remain employed (Kotlikoff\&Pozen, 2015). Congress could also eliminate the $12 \%$ social security payroll tax to employees over 70 years of age. The social security payroll tax adversely affects employees and employers; eliminating it may persuade older adults to remain working and provide incentives for employers to keep older workers employed (Kotlikoff\&Pozen, 2015).

\section{Highlighting benefits of employing older workers}

Governments in industrialized countries are mindful of delaying retirement among potential retirees through blended work. For example, the United Kingdom has commissioned intervention studies on blended work, examining factors such as the extent, nature, and effects of blended work at individual and organizational levels (DiMartino\& Wirth, 1990). Findings suggest that blended work could lead to new work opportunities for the un- or underemployed older worker and cost savings for businesses.

Seminars conducted by government could inform employers about research findings that focus on performance and the older worker. For example, studies suggest there is often little association among performance, age, and occupation, after accounting for knowledge, experience, and cognitive ability (Sharit et al. 2008; Warr, 1992). Information and awareness workshops by government could involve all stakeholders on future blended work scenarios and the suitability of various combinations of technology to promote blended work in older workers (DiMartino\& Wirth, 1990). National forums could showcase success stories of competent older workers completing assignments and satisfying their employers (Gillespie, Richardson, \&Cornford, 1995). Education at federal, state, and local government levels are needed to inform employers about the myths surrounding older workers and to implement policies to offset forced retirement (Burke \& Ng, 2006).

\section{CONCLUSIONS}

From the above discourse a short conclusion can be drawn on the various intricate in retirement for the general participants aging workforce.

When looking at the work initiatives the level in which the job is physically demanding, the status of the job and the status of the participant appear to be an important factor. Therefore this part of work circumstances will be difficult to test in the data analysis. However Wage might function as a representation of the physical demand of work.

Regarding family circumstances, the fact that spouses are in a lot of cases covered by their husbands' or wives' employer is an important influence. However, when this is not the case it can result that the husband may retire relatively earlier than the wife. This can be explained by the fact that wives are, according to research, better in combining work and family as opposed to their husband. 
Another factor concerning family circumstances is the marital status. There is always a spillover effect found, regarding when the effect of the retirement of one spouse on the other.

The financial incentives are ever more important to males than females. However the importance of the financial incentives itself is paramount the use of the Pension right and the Wage of the individual measure this variable during retirement.

Fiscal attractiveness can also play an important role, but research has shown that this role can be deceptive.

This literature suggests that specific subgroups of workers are more likely to blend work. Wellpaid, older white collar professionals with good technological and computer skills, older workers who require little work structure and work-home separation, and older workers who are self-reliant, motivated, and can work independently comprise some of the subgroups who would best fit a blended worker profile. Understanding linkages among cognitive abilities, aging, and technology are central to understanding why older workers perform at different levels than younger workers. One future research approach could involve conducting task analyses of actual blended work, followed by simulation scenarios in controlled environments. Such research should examine how technological advances in complex software and multimedia modalities, which can improve communication and interaction of blended work teams, affect psychomotor and cognitive performance among different age groups. These technologies differ in their information carrying ability and how accessible the information is for a given technology. These factors could affect an older worker to a greater extent than a younger worker due to an aging biological system. As our understanding evolves about how technological advances affect older workers, the likelihood of blended work as a successful bridge between traditional employment and retirement in older workers should improve.

Ultimately, for blended work to be successful among older workers, the "perfect storm" may be required: state standards and legislation, organizational incentives and policies structured to support blended work, and managements' willingness to employ older workers in blended work and provide them with appropriate equipment.

\section{References}

Anonymous (1998). Retirement Planning. Tax ManagementFinancial Planning Journal, 14, 4648.

Bell, J. H., \& Rauf, R. C. (1998). A graphical approach toretirement and estate planning. Journal of Finance ServiceProfessionals, 52, 72-81.

Benartzi, S. \& Thaler, R. H. (1999). Risk aversion ormyopia? Choices in repeated gambles and retirementinvestments. Management Science, 45, 364-381.

Betts, A. (2003). The value of asset allocation. TexasBanking, 92, 22.

Blair, D. T. \& Sellars, A. T. (1995). More than investmenteducation. Journal of the American Society of CLU \&ChFC, 49, 64-71.

Centers for Medicare and Medical Services Office of theActuary (2001). National Health ExpendituresProjections: 2001-2011.

Everett, M. D. \& Anthony, M. S. (1996). Abstract retirement planning using Modern Portfolio Theory. Journal of AssetProtection, 1, 65-71.

Haas, D. R. (2001). Assessing retirement income. Advisor Today 96(8), 78-79.

Hager, G. (1999). Want a shock? Do the numbers online. The Washington Post, H 07.

Health Insurance Association of America (2002). Issue Brief: Why do health insurance premiums rise.Levy, J. \& Young, M. (2002). Replacement ratio redux.Benefits Quarterly, 18, 22-31. 
Haas, D. R. (2001). Assessing retirement income. Advisor Today 96(8), 78-79.

Hager, G. (1999). Want a shock? Do the numbers online. The Washington Post, H 07.Health Insurance Association of America (2002). Issue Brief: Why do health insurance premiums rise.

Levy, J. \& Young, M. (2002). Replacement ratio redux.Benefits Quarterly, 18, 22-31.Palmer, B. A. (1994).

Retirement income replacement ratios:

An update. Benefits Quarterly, 2Q, 63-66.Smith, K. V. (1997). Stocks versus bonds in retirement planning. Journal of Financial Planning, 10, 87-90.

Stein, M. K. (1999). Getting to 'yes' in retirement planning.Journal of Financial Planning, 12, 30-31.

Stern, L. (2000). Do you really need millions to retire. Better Homes and Gardens, 78, 21-25.

Tacchino, K. \& Saltzmann, C. (1999). Do accumulation models overstate what's needed to retire? Journal ofFinancial Planning, 12(2), 62-74.

Tax Management Financial Planning Journal (1998).Retirement Planning, 14, 46-49.

Tiffany, G. (2003). Public employee retirement planning.Employee Benefits Journal, $28,3$.

The United States Census Bureau (2000). StatisticalAbstracts of the United States, Parks, Recreation andTravel. United States Department of Health and Human Services(2001). Health Care Financing Administration. 